Espaço Aberto | Open Space

\title{
A casa e a rua em tempos de Covid-19: uma leitura antropológica de "Diário de confinamento" (Susana Bragatto)
}

House and street in times of COVID-19:

an anthropological reading of 'Diário de confinamento' (Susana Bragatto)

Heitor Frúgoli Jr. *

*Universidade de São Paulo - São Paulo, SP, Brasil

hfrugoli@uol.com.br

https://orcid.org/0000-0002-9075-891X 


\title{
Resumo
}

Análise do diário de Susana Bragatto a partir da decretação do estado de alarme na Espanha, em virtude da pandemia do coronavírus, publicado na Folha de S. Paulo entre março e junho de 2020. São analisadas especificidades das dinâmicas de isolamento social e desconfinamento específicas ao contexto europeu, com atenção às novas configurações dos usos dos espaços domésticos e sobretudo às formas de interação face a face nos espaços públicos na cidade de Barcelona, onde reside a autora, nascida no Brasil. Ao final são tecidos breves contrapontos com a experiência brasileira, mais especificamente em São Paulo, com atenção a impactos da pandemia na vida urbana.

Palavras-chave: pandemia; diário; interações; vida urbana.

\begin{abstract}
Analysis of the diary written by Susana Bragatto after the decree of the state of alarm in Spain, due to the coronavirus pandemic, published in Folha de S. Paulo between March and June 2020. I analyze the specificities of social isolation and end of lockdown dynamics specific to the European context, with attention to the new configurations of the uses of domestic spaces and, above all, to the forms of face-to-face interaction in public spaces in the city of Barcelona, where the author, born in Brazil, has lived. At the end, I make brief counterpoints to the Brazilian experience, more specifically in São Paulo, with attention to the impacts of the pandemic on urban life.
\end{abstract}

Keywords: pandemic; diary; social interactions; urban life. 


\section{Introdução: cem dias que abrem indagações teóricas e existenciais duradouras}

No rol avassalador de perguntas que emergem com o advento da atual pandemia, sublinha-se o que passa a ser possível pesquisar, do ponto de vista etnográfico, frente às restrições de várias ordens às interações sociais face a face, dada a necessidade de isolamento e dos diversos cuidados necessários para se evitar a transmissão da Covid-19. Isso passou a exigir da antropologia, em vários casos, não apenas novas formas de investigação, ${ }^{1}$ bem como tem levado à intensificação de debates e de produção de textos. Ressalta-se a necessidade de projeções do espaço acadêmico à esfera pública, dada a premência do enfrentamento político, científico e ético de uma conjuntura que, se no caso brasileiro já apresentava dificuldades consideráveis nos últimos anos, aprofundou-se em sua dramaticidade. ${ }^{2}$

Diversos termos ${ }^{3}$ que passaram a habitar nosso cotidiano estarão presentes neste texto, com significados por vezes cambiantes e que deslizam em sua aplicação:

a) quarentena - que em geral passou a designar uma reclusão pelo período de duas semanas, ${ }^{4}$ voltada a pessoas que não estão doentes, mas possivelmente

1 Uma fala sobre horizontes da etnografia durante a pandemia, com certa repercussão nesse período, foi a do antropólogo Daniel Miller em evento do World Council of Anthropological Associations (WCAA) em 19/5/2020, traduzida para o português pelo Laboratório de Imagem e Som em Antropologia (USP) (ver Miller, 2020).

2 Refiro-me à crise política brasileira dos últimos anos, com desdobramentos em muitos planos. Muito concisamente, isso remete às manobras que levaram ao impeachment da presidente Dilma Rousseff (agosto de 2016), ao assassinato da vereadora carioca Marielle Franco (março de 2018), à ascensão da extrema direita ao poder com a eleição presidencial de Jair Bolsonaro (outubro de 2018), aos sucessivos desastres e devastações ambientais (Minas Gerais, nordeste e sudeste do litoral brasileiro, Pantanal, Amazônia), à interrupção de diversos programas sociais e ao aumento das desigualdades. Com a concretização da pandemia no país a partir do início de 2020 e o papel deletério do governo federal - não apenas ao recusar a letalidade da Covid-19, mas ao sabotar iniciativas voltadas a algum planejamento consistente de enfrentamento da propagação do vírus -, configurou-se a concomitância das crises política, sanitária e financeira (para sugerir apenas uma entrevista a respeito, ver Latour, 2020).

3 Alguns definidos ou redefinidos pela Organização Mundial da Saúde (OMS).

4 Devido ao tempo de incubação do vírus da Covid-19. 
expostas ao vírus, embora também venha sendo usada por autoridades para decretar a restrição de determinadas atividades por 40 dias; ${ }^{5}$

b) distanciamento social - que abarca um conjunto amplo de medidas para evitar a propagação do vírus, o que inclui o fechamento temporário de diversas instituições (locais de trabalho, ensino, lazer, religião, comércio, etc.); adoção, quando possível, de home office (escritório em casa); evitação voluntária de quaisquer aglomerações; manutenção da distância, nos espaços públicos, entre pessoas (1,5 a $2 \mathrm{~m}$ ); uso preventivo de máscaras de proteção;

c) isolamento social - termo de certa forma englobado pelo anterior, que remete em geral a permanecer em casa, de forma voluntária ou involuntária, e que se traduz numa variação de situações, a depender dos arranjos domésticos (como morar só, com parceiras(os), com famílias nucleares ou ampliadas, com amigas(os), etc.) e da própria condição de moradia (apartamentos, casas, sobrados, cortiços, barracos, etc.);

d) lockdown - em português, confinamento, que remete a um bloqueio sanitário promovido pelo Estado, ${ }^{6}$ com o controle explícito da circulação (a não ser para atividades essenciais, como compra de alimentos, ou idas a farmácias ou hospitais), e que pode levar, além de advertências, à aplicação de multas; tal prática foi adotada de forma ampliada na China e em vários países asiáticos e europeus, e de forma apenas pontual e local em certas cidades ou regiões brasileiras.

De modo geral, vários usos dos espaços urbanos têm sido efetivamente impactados pela pandemia, ${ }^{7}$ embora isso não tenha de se dado, evidentemente, de forma homogênea. Os fatores guardam relação com a diversidade de escala dos contextos urbanos existentes (metrópoles, megacidades resultantes de conurbações, cidades de médio ou pequeno porte, etc.) bem como a heterogeneidade constitutiva do próprio âmbito urbano (áreas centrais ou periféricas, de uso

5 Ao longo do tempo, esse termo passou a se confundir com distanciamento ou isolamento social.

6 Por vezes, sob a decretação de estado de emergência ou de alarme (como veremos à frente, no caso da Espanha).

7 Sem abordar, aqui, os abalos consideráveis da Covid-19, no caso brasileiro, em populações como as indígenas, além das quilombolas e ribeirinhas. 
misto ou residencial, em que a disponibilidade de infraestrutura urbana e, inversamente, o grau de vulnerabilidade constituem fatores determinantes a se levar em conta). Isso sem falar de outras variáveis em jogo, que dizem respeito, no presente enfoque, às nações ou regiões em que tais cidades estão inseridas, às formas como a pandemia Covid-19 se configurou e como foi ou não enfrentada por políticas dos respectivos governos, em seus diferentes níveis decisórios.

Cabe também ressaltar que os efeitos da pandemia na vida urbana se articulam a crises e desigualdades anteriores em andamento, assinaladas por uma significativa historicidade ${ }^{8}$ a desafiar tanto os habitantes quanto os responsáveis pelas políticas públicas. Torna-se assim mais problemática a busca de compreensão do presente pandêmico nos contextos urbanos. ${ }^{9}$

Este artigo busca contribuir através de um enfoque mais detido numa dimensão evidentemente afetada nesses tempos recentes, sobretudo durante a intensificação das restrições da circulação fora de casa, o que remete às diversas formas de interação nos espaços públicos (Agier, 2011; Goffman, 2011; Joseph, 2000; Paquot, 2009; Simmel, 2006) - alvo de enfoques de longa data pela antropologia urbana (Frúgoli Jr., 2007). ${ }^{10}$

Busca-se, portanto, captar aspectos assinaláveis do isolamento social, com o confinamento doméstico que levou a certo esvaziamento dos espaços públicos ou de acesso público - algo que adquire, como já frisado, escalas, modalidades e características contextuais muito distintas, a depender dos países ou regiões afetadas, bem como os agentes envolvidos, em suas demarcações de classe, gênero, raça, dentre outras. Pretende-se captar especificidades desse confinamento a partir das relações entre casa e rua, já clássicas na antropologia (DaMatta, 1980, 1985), levando em conta os contextos e repercussões advindas

8 Robert Park (1987, p. 45) já postulava, no início do século XX, que "as cidades, e especialmente as grandes cidades, estão em equilíbrio instável", e em consequência, "numa condição de crise crônica", salvo estabilizações pontuais.

9 O enfrentamento dos impactos nos espaços públicos constitui tema de agenda da Organização das Nações Unidas: "A pandemia da Covid-19 tem alterado drasticamente nossas relações com nossas ruas, espaços públicos e equipamentos públicos [...] Conforme as cidades começam a se abrir do bloqueio sanitário, precisamos reconstruir a confiança para com o espaço público durante e após a pandemia" (United Nations Human Settlements Programme, 2020, p. 2, tradução minha).

10 Sem detalhar aqui uma vasta lista de autores referenciais. 
da pandemia, que têm levado a certa proeminência, a princípio, da casa sobre a rua, ainda que neste artigo se priorize o enfoque em interações nos espaços públicos.

Numa brevíssima genealogia, a relação entre os âmbitos da casa e da rua tornou-se referencial na antropologia brasileira sobretudo a partir de Carnavais, malandros e heróis (DaMatta, 1980), quando o autor lançou as bases de uma abordagem ensaística sobre a sociedade nacional, ${ }^{11}$ depois de sua experiência anterior como etnólogo. ${ }^{12}$ Tal binômio casa-rua, inserido na busca de uma explicação holística sobre a sociedade brasileira, veio a ser retomado e matizado em diversos estudos etnográficos posteriores, como na abordagem sobre significados de interações populares nas ruas do bairro carioca do Catumbi (Vogel; Mello, 2016); o papel de famílias matrifocais do bairro da Liberdade na circulação de mulheres e homens por espaços urbanos de Salvador (Agier, 1990); as relações entre moradores de bairros soteropolitanos populares baseadas em princípios de parentesco de "sangue" e "consideração" (McCallum; Bustamante, 2012); os enfoques sobre casas partíveis ${ }^{13}$ e relações de vicinalidade (proximidades abertas entre espaços de morada) (Pina-Cabral; Godoi, 2014).

Apesar da pertinência inegável de tais enfoques, entendo que gradativamente se afastam de uma compreensão mais precisa de relações de sociabilidade nos espaços urbanos, sobretudo em metrópoles ou cidades de grande porte. Dessa forma, pode-se dizer que as relações entre casa e rua estarão presentes neste texto como um valor heurístico, embora sem uma ênfase na dimensão do parentesco, ainda que pudessem vir a sê-lo em abordagens sobre impactos da pandemia. ${ }^{14}$

As dinâmicas da pandemia também ensejam outra polaridade fundamental nos estudos urbanos, entre cidadania e citadinidade (Joseph, 2005), entendida

11 Em diálogo com a antropologia de Lévi-Strauss, Dumont e Turner, e com autores do pensamento social brasileiro, como Sérgio Buarque de Holanda e Gilberto Freyre (também situado no campo da antropologia).

12 Fernanda Peixoto (2000) aventa que a etnografia do autor entre os Apinayé foi importante para suas primeiras formulações teóricas sobre a sociedade brasileira, quanto às oposições estruturais entre o mundo público e o privado (ver também Frúgoli Jr., 2000).

13 Em diálogo com autoras como Marilyn Strathern.

14 Quanto ao modo, p. ex., como vínculos entre parentes ou amigos têm sido reforçados ou redimensionados quanto às formas possíveis de interação. 
aqui sobretudo como a necessidade ou expectativa de que sejam respeitadas determinadas regras e etiquetas, em contraste com as formas concretas e transgressivas com que muitas vezes podem ser usados ou reocupados os espaços públicos. Em outras palavras, trata-se de lembrar que a figura do citadino ${ }^{15}$ não se reduz à figura do transeunte, tampouco coincide, como aponta Isaac Joseph (2005), com a do cidadão (embora possa eventualmente englobá-la). A urbanidade, dessa forma, não conduz a priori às práticas de cidadania, e nem sempre a cidade, por suas conjunções instáveis, produz aglomerações politizadas (Frúgoli Jr., 2007, p. 7). Para Joseph (2005, p. 122-124), as dinâmicas de copresença no espaço público, que se revelam ao final de uma pesquisa, não podem constituir um pressuposto, a não ser num plano abstrato; em outras palavras, o espaço público constitui menos um espaço consensual do que de desterritorialização. ${ }^{16}$

Pretende-se, assim, explorar as temáticas até aqui delineadas através da leitura detida de um diário específico, escrito por Susana Bragatto, nascida em Recife, jornalista, cantora e compositora, com mestrado em Teoria Literária e Literatura Comparada na USP (2007), residente há anos em Barcelona (dia\#8, 21/3), publicado na Folha de S. Paulo entre março e junho (Bragatto, 2020), como um contraponto para um olhar sobre nossas próprias vivências, dificuldades e reflexões durante a pandemia (especialmente em São Paulo, metrópole onde vivo). ${ }^{17}$

Embora não pretenda me aprofundar nos estilos ou estratégias textuais (Geertz, 2002) de diários e seus significados, cabe demarcar parâmetros que norteiam a análise. Felipe Charbel (2020) escreveu um artigo oportuno sobre o assunto. Autor de um diário de sete anos, pondera sobre os novos significados de tais escritos a partir da pandemia, na qual, praticante do isolamento, passou

15 “....] que ocupa espaços urbanos, desloca-se por seus territórios e trava relações de proximidade e distância com outros citadinos, em contextos específicos e situados" (Frúgoli Jr., 2007, p. 7). Sobre relações de proximidade e distância, ver Simmel (2005), cujos escritos, do início do século XX, são referenciais na presente abordagem..

16 Para o diálogo dessa perspectiva analítica com a abordagem de Erving Goffman (1922-1982), ver Joseph (2000). Para uma abordagem abrangente sobre múltiplos significados do espaço público, contrapondo conceitos clássicos e usos e práticas cotidianas, ver Paquot (2009).

17 Agradeço pelo debate sobre os diários com integrantes do Grupo de Estudos de Antropologia da Cidade (GEAC-USP) em 23/7/2020: Eduardo Rumenig, Flavia de Faria, Júlia Daher, Julio Talhari, Maurício Alcântara, Simone Toji e Wesllen de Souza. Sou também grato aos comentários e sugestões das(os) pareceristas do presente artigo. 
a registrar as flutuações de seu próprio desânimo (Charbel, 2020, p. 114). Ele lembra que "manter um diário em público não é igual a escrever apenas para si" (Charbel, 2020, p. 116), mas, para além da ambiguidade entre escrever para si ou para leitores, ${ }^{18}$ o diário constitui "um tipo peculiar de convívio, um posicionamento diante do mundo, uma forma de cuidar de si" (Charbel, 2020, p. 118). ${ }^{19}$ Algo que pressupõe certo gosto pelo recolhimento (regido pela vontade), o que é distinto de um isolamento (compulsório), sem brechas, como para uma eventual caminhada a esmo pelas ruas, aberta ao acaso - "sem a urgência de voltar correndo para a cela e me desinfetar num banho aflito" (Charbel, 2020, p. 121).

Sobres essas últimas observações, vale recuperar passagens do diário de Susana Bragatto: "Existe uma diferença abismal entre decidir não sair e não poder sair" (dia\#16, 29/3); "Eu faço parte da ala predominantemente introspectiva da humanidade. Adoro gentes, mas busco e preciso de boas doses de minha solidão pra criar, refletir, me equilibrar" (dia\#50, 2/5); "Este é um momentum de baixar expectativas e sorver a simplicidade dos pequenos prazeres" (dia\#60, 12/5).

Com base nesses apontamentos teóricos e metodológicos, passemos à reconstituição específica de passagens do diário da autora, com atenção ao movimento inicial de confinamento (assinalado pelo lockdown) e de ênfase no espaço doméstico - "encaixotada em um apartamento no centro de Barcelona", com um "companheiro de apartamento" (dia\#8, 21/3), no bairro de La Sagrera e às novas dinâmicas nas ruas. Aos poucos, a diminuição da curva de óbitos e de infecções da Covid-19 levam ao desconfinamento (ou desescalada ${ }^{20}$ ), tão ou mais desafiante que o próprio confinamento, como se depreende de diversas passagens do diário, cuja ênfase se volta à complexidade política de tais decisões e à ampliação da narrativa sobre diversas interações e usos dos espaços urbanos de Barcelona.

18 Como sabemos, o diário que Malinowski (1997) escreveu para si sobre a experiência entre os trobriandeses suscitou uma série de polêmicas ao ser publicado post mortem, o que ocasionou reflexões como a de Geertz (2003).

19 Para a leitura de diários marcada pela radicalidade do termo, ver dois livros de Ricardo Piglia (2017, 2019), centrados, num jogo entre vida pessoal e ficção, em seu alter ego Emilio Renzi.

20 Termo idêntico em espanhol e português, não usado no Brasil a partir da pandemia; na linguagem do alpinismo, significa descida, mas também consiste no abrandamento ou reversão de uma crise ou conflito. 


\section{Estado de alarme e desescalada em Barcelona}

O aumento altamente preocupante de casos e óbitos espanhóis - que a certa altura superara a China e também a Itália, além de um elevadíssimo número per capita (de infecções e falecimentos) - levou à decretação do estado de alarme (estado de alarma) no país a partir de 14/3/2020 (Cué; Pérez; Blas, 2020), justamente quando começa o referido diário. O lockdown, decretado pelo governo, foi reforçado por ações policiais em alto-falantes, seguidas de interpelações em praias, bulevares e calçadas (dia\#2, 15/3). As denúncias contra usos indevidos das ruas cresceram exponencialmente no país: mais de $30 \mathrm{mil}$, com 350 detenções (dia\#9, 23/3), saltando, em uma semana, para mais de 180 mil (dia\#17, 30/3), com mais de 1,5 mil detenções e 7 mil multas; ${ }^{21}$ após 20 dias, as denúncias já totalizavam mais de 650 mil (dia\#31, 13/4). Nesse período inicial, frente à insuficiência de testes de Covid-19 a toda a população, uma porta-voz do governo afirmou que "o único tratamento que temos agora é a disciplina do conjunto de cidadãos" (dia\#14, 27/3).

$\mathrm{Na}$ fronteira do espaço privado com o público, surgiram aqueles que passaram a vigiar práticas ilícitas de suas sacadas (daí o apelido de policía de balcón), com eventuais insultos aos transeuntes: "Volta pra casaaaaa! [...] Há casos de gente que joga ovos, xinga ou cospe em quem está na rua", o que por vezes atingia "profissionais de saúde e trabalhadores de outros serviços básicos que seguem ativos" (dia\#17, 30/3). ${ }^{22}$ Uma profissional (caixa de supermercado) encontrou esta mensagem anônima na porta do domicílio: "Queremos pedir a você pelo bem de todos que busque outra casa enquanto isso dure [...] Não queremos riscos. Gracias" (dia\#32, 14/4).

As idas iniciais às ruas para atividades básicas e permitidas, como mercado ou posto de saúde das cercanias, passam a simbolizar aventuras (dia\#2, 15/3). "No caminho, apresso o passo. Cruzo com mais gente do que esperava. Os olhares são furtivos, todos parecem determinados a chegar não sei aonde o mais rápido possível. Solitários, em sua maioria" (dia\#3, 16/3). Uma simples saída

21 Variáveis entre 100 e 600 euros.

22 ' 'Rata contagiosa'. Com essas palavras pichadas em seu carro, uma médica de Barcelona foi ao trabalho" (dia\#34, 16/4). 
envolve uma série de preparos: “[...] luvas, máscara, e cartão de identidade com o endereço da casa [...] Chego à porta do supermercado. Fila na calçada. Silêncio mortal" (dia\#9, 23/3). "À entrada [do supermercado], um funcionário com figurino de astronauta sinaliza o álcool em gel [...] A distância de um metroooo! E eu demoro microssegundos pra perceber que é comigo. Eu infringi uma linha invisível que nos separa a todos. Bad, bad girl" (dia\#16, 29/3). Num momento mais angustiado, ela escreve: "O que é um ser humano nas breves andanças do confinado? Um obstáculo a evitar" (dia\#26, 8/4).

Após semanas, ampliam-se andanças de redescoberta da cidade: "É a primeira vez desde o princípio do confinamento que me aventuro pra além da esquina de casa. Já tinha esquecido que havia outras ruas, esquinas, pessoas. Sim; muitas pessoas [...] dois homens conversam numa esquina; fila na farmácia; um adolescente partindo em patinete ri e grita despreocupadamente a seus amigos: “Tira essa máscara, hombre, morre como um valente!"” (dia\#40, 22/4). ${ }^{23}$

O uso do dinheiro impresso diminui substancialmente (dia\#6, 19/3), e meses depois o próprio governo anuncia sua eliminação gradual e possível desaparição: a autora percebe que quase não carrega mais dinheiro consigo, embora isso não valha em pequenas lojas; "creio que ao longo do confinamento fui só uma vez ao banco"; trocados são guardados em "tilitantes bolsinhas", "no augúrio de dias melhores" (dia\#93, 14/6).

Novas estratégias de encontro entre casais separados pelo coronavírus envolvem encontros "casuais" em espaços de acesso público - "uma caixa de supermercado se queixa de que tem que enxotar casais jovens do estabelecimento" - ou, então, intensifica-se o uso de aplicativos de encontro: "Tenho conhecidos com dificuldades em administrar tantos coronamatches e futuros-quiçás-dates"; ela também relata, sobre casais que dividem a mesma casa,

23 Num momento mais avançado da pandemia, o escritor e jornalista John Freeman (2020) aborda desigualdades de Nova York, através de caminhadas pelas ruas: "Percorrer quarteirões para cima e para baixo é sentir uma cidade estremecendo". No mesmo artigo, ele descreve: "Alguns meses atrás eu estava caminhando por um bulevar no Midtown, conversando com um homem que emergira das sombras onde outros dormiam. Ele queria dinheiro para comprar um sanduíche [...] Eu lhe dei US\$ 3 e continuei andando em direção ao centro" (Freeman, 2020). Mais à frente, observou uma vitrine de uma loja de mobília modernista com preços impensáveis: “Quem é que compra um sofá por US\$ 100 mil durante uma pandemia?” (Freeman, 2020). 
“[...] que estão passando o confinamento juntos numa boa. E alguns que se separam. E seguem vivendo juntos. Até que o fim do confinamento os separe" (dia\#22, 4/4).

As expressões faciais, referências significativas em interações, se redimensionam com o uso das máscaras: "Nunca fui boa fisionomista. E, agora, com as onipresentes máscaras, ${ }^{24}$ só nos resta tentar ser bons olhistas. Na calçada, dou passagem a uma mãe com uma bebê bunitinha num carrinho. Eu sorrio, ela sorri. Acho. Sorrisos invisíveis [...] Teremos que adaptar nossa expressão emocional ao âmbito ocular? Perderemos sutilezas da cordialidade não verbal?" (dia\#46, 28/4).

Dentro da(s) casa(s), em contraponto à desertificação inicial das ruas - e não sem dificuldades, apreensões, ansiedades e angústias - condensa-se um amplo cenário de atividades, novas rotinas, conexões virtuais, trocas de informações, busca de notícias, audiência de lives, compassos de espera, meditação, mindfulness (e correlatos) e novas percepções. ${ }^{25}$

Vejamos algumas cenas: "Roupas no varal, casa desinfetada, tevê na Netflix [...] Posts/memes/teorias conspiratórias (e receitas de bolo de caneca)" (dia\#2, 15/3). "Pela primeira vez, ouço em toda a sua glória a fauna da árvore em frente ao prédio" (dia\#4, 17/3). "Um quadrinho que está circulando diz que depois que isso passar nós vamos sair do cativeiro obesos, divorciados, grávidos, loucos" (dia\#8, 21/3). "Em casa, o repetitivo trajeto quarto-sala-banheirovaranda amplifica a sensibilidade ao detalhe. $O$ pó no canto da cozinha é mais evidente, o vinco na cobertura do sofá e as orquídeas abrindo uma a uma, o movimento das pétalas reverberando primaveras no ar da sala [...] Por sorte, tenho em casa domínio quase absoluto do escritório, onde montei um QG" (dia\#29, 11/4). "As campanhas (de loja de móveis, carro, banco, caldo de galinha, não importa) migraram para a vida indoor, mostram gente na janela em coreografia jovial de acenos solidários, famílias em convívio fraternal,

24 "A partir desta quinta, máscaras passam a ser obrigatórias em toda a Espanha, não só em espaços fechados como em áreas ao ar livre onde não se possa manter a distância de dois metros. A multa para os desobedientes: 600 euros (R\$ 3.750)" (dia\#68, 20/5).

25 Embora de crescente importância, o âmbito doméstico não será, como já dito, a tônica deste artigo. 
casais acucurraditos no sofá" (dia\#32, 14/4). "O ciudadano confinado pode ter a sensação de estar flutuando numa nave em zero gravidade, segunda = domingo = terça $=$ anteontem, mas o tempo lá fora (meus olhos passeiam até a janela: nublado, o branco fantasmagórico emoldurado de garoa e skyline cor de terracota barcelonês)... ainda pulsa taquicárdico a cada início de nova semana" (dia\#38, 20/4).

Mas a própria casa apresenta percalços para além da proteção contra o vírus. Frente à indisponibilidade de confinamentos não domiciliares para positivos assintomáticos, resta um isolamento dentro de outro: “[...] com sintomas leves de resfriado, e sem poder fazer o teste, reservado aos pacientes graves, fui orientada [...] a isolar-me preventivamente por pelo menos duas semanas dentro de casa. Detalhe: em nosso apê, há só um banheiro, como a maioria dos lares barceloneses" (dia\#25, 7/4). Meses depois, a vendedora de uma loja do bairro lhe conta de um trabalho temporário num hospital público, recrutado por uma empresa de limpeza: "Mãe de dois filhos, de 11 e 13 anos, Geni passou esses dois meses de trabalho no hospital isolada da família dentro da própria casa [...] Cada dia, ao chegar em casa, eu guardava a roupa de rua numa sacola, tomava banho e me isolava em um quarto longe dos meus filhos e marido" (dia\#95, 16/6).

Proliferam as práticas de solidariedade: produção de máscaras ${ }^{26}$ doações de sangue, voluntariado para ajudar a população idosa desassistida, auxílio a pessoas que vivem nas ruas, oferecimento de ajuda com crianças, compras e cuidados médicos, apoio a pacientes hospitalizados (dia\#7, 20/3). Em sintonia com tais atitudes, as sacadas e varandas dos edifícios, além de local de contemplação e de vigilância, também se tornam espaços de exercícios de solidariedade coletiva, como as salvas de aplausos aos profissionais de saúde que passam a ocorrer diariamente às 20h: "É o momento de comunhão da vizinhança, e um ritual para lembrar-nos uns aos outros por que estamos aqui encaixotados" (dia\#7, 20/3). Mas vieram a minguar a partir do desconfinamento gradativo (dia\#48,30/4), até que cessassem: "Na quarta, às $20 \mathrm{~h}$, saí para o já clássico 'aplaudiment' [...] Choque: silêncio total. Um homem lá longe bate

26 “Uma amiga minha de Marselha, pródiga em habilidades manuais [...] já está fabricando belas máscaras protetoras (nunca pensei que diria isso) com estampa de flores, listras etc. Inicialmente para amigos, começou a receber pedidos, muitos" (dia\#36, 18/4). 
palma, solitário. Eu o sigo. E as pessoas começam a olhar pra cima - pra me ver. Intrigadas. Seus olhinhos sobre máscaras parecem acusar: quem é essa louca?" (dia\#69, 21/5).

Não há menção a assédios a ela ou a outrem nas ruas, mas "as denúncias por violência de gênero sofreram um boom no confinamento espanhol. Só em abril, auge da pandemia no país, registrou-se aumento de $60 \%$ nas ligações ao $016^{27}$ em relação ao mesmo período em 2019" (dia\#97, 18/6). Segundo ela, "também se encorajou a colaboração cidadã de vizinhos e familiares para identificar e denunciar casos de violência. O Ministério da Igualdade lançou a campanha 'Estamos contigo. \#Tudoirábem', com conselhos sobre como atuar em diversas situações e cartazes distribuídos em comunidades, mercados e farmácias" (dia\#97, 18/6). Segundo estudo do Observatório contra a Violência Doméstica e de Gênero (vinculado ao Poder Judiciário), com dados desde 2003, "em 75\% dos casos, o crime ocorreu dentro de casa" (dia\#97, 18/6).

Susana Bragatto é paciente de um câncer em remissão, e por integrar uma rede de ex-pacientes ouve pela primeira vez, de uma psicóloga de uma $\mathrm{ONG}^{28}$ que o confinamento poderia vir a constituir uma experiência com caráter permanente: "O que estamos vivendo não é um parêntese que tenhamos que atravessar o quanto antes para poder retomar nossa vida [...] Os dias que estamos vivendo são nossa vida agora" (dia\#36, 18/4). É sob o signo dessa espécie de "consenso interdito sobre a ideia de uma Nova Normalidade"29 (dia\#36, 18/4) que começa a se esboçar a assim chamada desescalada, vinculada a expectativas do verão europeu, muito aguardado numa cidade litorânea e turística como Barcelona.

Se o confinamento através do lockdown aparenta ser sido, do ponto de vista de sua gestão, politicamente consensual, o anúncio da desescalada pelo governo - em quatro etapas, com avanços assimétricos, a depender do quadro epidemiológico de cada província, com protocolos complexos sobre setores abarcados e

27 “O número está destinado a consultas, assessoramento jurídico e atendimento de emergência a vítimas" (dia\#97, 18/6).

28 Para pacientes de câncer de mama de Barcelona.

29 “....] a das conexões virtuais, da ida ao supermercado, da vida pela janela, dos aplausos das $20 \mathrm{~h}$, das máscaras obrigatórias, dos abraços de longe, da expectativa longínqua de que tudo isso acabe" (dia\#36, 18/4). 
delimitações dos tipos de uso - abriu diversas interrogações (dia\#46, 28/4). Isso veio a configurar enfrentamentos políticos tanto partidários quanto regionais (ligados a certa tradição separatista, como bascos e catalães): “Catalunha está entre os territórios mais cautelosos com a desescalada. Por outro lado, Madri, já insistiu de novo que quer ser 'promovida ${ }^{30}$ na semana que vem, alimentando um impasse de forças com o governo" (dia\#59, 11/5). Em Madri, passou a haver protestos conservadores: “Hoje é o quarto dia em que manifestantes vão às ruas de bairros nobres [...] para protestar contra o governo e contra o prolongado estado de emergência", cujos bairros "figuram entre os 11 distritos mais ricos da Espanha [que] concentram um grande eleitorado direitista" (dia\#62, 14/5). ${ }^{31}$

A primeira experiência de desconfinamento foi paradigmática. $O$ governo anunciou que, antes do fim de abril, as crianças poderiam voltar às ruas, de forma monitorada (dia\#37, 19/4), com o informe posterior de que menores de 14 anos (mais de 6,8 milhões no país) poderiam sair com pais ou responsáveis, em andanças como ida ao mercado ou farmácia (dia\#39, 21/4). Dias depois, liberou-se o passeio em até uma hora por dia, e cada adulto poderia acompanhar até três crianças, mantendo-se a distância de $2 \mathrm{~m}$ entre os núcleos familiares, além da não mistura de brinquedos entre tais núcleos, com o uso de máscaras nas crianças não mais obrigatório, apenas sugerido (dia\#42, 24/4).

No domingo que marcou a primeira experiência concreta, a autora relata que "vídeos e fotos feitos em toda a Espanha circulam nas redes sociais e mostram multidões de famílias em algumas avenidas e praças principais [...] No Passeig de Gràcia [...] era tanta gente que simplesmente não sobrava espaço para manter as regras de distanciamento social" (dia\#44, 26/4), o que suscitava desconfiança sobre a desproporção entre crianças e adultos previamente estipulada. No dia seguinte, internautas revoltavam-se: “[...] pais\&filhos amontoados em praias e centros urbanos (além de uns tantos adultos sem prole)", cuja imprudência gerou indignação inclusive de profissionais de saúde: "Preparem-se para os 'rebrotes' [novos surtos de contágio], ${ }^{32}$ isto não terminou" (dia\#45, 27/4).

30 Quanto à fase da desescalada.

31 Antes disso, o diário havia registrado panelaços pontuais em todo o país (caceroladas), das janelas e sacadas, às $12 \mathrm{~h}$ e às $21 \mathrm{~h}$, contra um escândalo milionário da realeza espanhola (dia\#5, 18/3).

32 Colchetes da autora. 
O tema da cidadania adquire, nos relatos, múltiplas facetas. Já vimos como isso emergiu no já citado incentivo à vigilância pelo isolamento. Com o início do desconfinamento, e tendo em vista o episódio (das famílias nas ruas) já mencionado, voltam os apelos à responsabilidade cidadã: "Agora, segundo o governo, vem a parte 'mais perigosa e mais difícil'. Os 'protagonistas' da desescalada, disse Sánchez em discurso sentimental-comedido hoje pela tevê, 'são os cidadãos'. Com nosso sorriso Mona Lisa" (dia\#46, 28/4).

Há pistas, nos escritos, de que os temores advinham das indefinições do próprio governo quanto à complexidade das novas regras, bem como da expectativa de que houvesse um (abstrato) senso ético por parte da população: "Aplicar o estado de emergência foi fácil', declarou à imprensa um ministro não identificado [...] Por outro lado, voltar às nossas vidas de antes... É muito difícil. Os protocolos não estão adiantados nem maduros e dependem de muitos fatores" (dia\#45, 27/4).

A partir de então, com a gradativa liberação dos espaços urbanos, várias passagens alternam-se entre o desejo de sair às ruas e a avaliação quase individualizada dos riscos envolvidos, com experiências ambivalentes: "Outra amiga, que mora perto da praia, desceu toda a 'rambla' (passeio) ${ }^{33}$ do bairro pra ver o mar: 'Havia muitíssima gente... E a sensação é que eu estava em um filme. De terror', disse. 'Todo mundo se olha de uma maneira estranha' [...] 'Foi como retornar de uma viagem longa', comentou meu cunhado. 'É um pouco estranho... Tudo está igual, mas nós não somos os mesmos"” (dia\#51,3/5). Dias depois, explicita-se o seguinte: "Até que ponto o governo poderá confiar na corresponsabilidade social da desescalada para evitar novos surtos? A autovigilância cidadã é tão frágil a ponto de poder se desintegrar com um simples 'vamo dar um rolê aí, amiguis, que se $\mathrm{f \# \# \#} \mathrm{o} \mathrm{tal} \mathrm{vírus?"'} \mathrm{(dia \# 52,} \mathrm{4/5).}$

Nossa protagonista aprecia uma nova cotidianidade nas ruas, embora na distância segura da varanda de seu apartamento: cedo, saem os madrugadores (para footing, pedalada, corrida); por volta das $10 \mathrm{~h}$ até meio-dia, aparecem os idosos, com carrinhos de compra ou cachorros; vê-se também casais de mãos dadas, outros circulam sozinhos; ocorre uma reunião improvisada na esquina, com saudações à distância; à tarde, predominam crianças; anuncia-se a

33 Parênteses da autora. 
abertura das praias para práticas esportivas (dia\#56, 8/5). ${ }^{34}$ Ela também observa que, pelas ruas, "as pessoas meio que gritam entre si. A voz do Novo-Papo-adois-metros é mezzo esganiçada, mezzo amistosa-agressiva" (dia\#70, 22/5). Com a entrada de Barcelona na fase 1 , "vou finalmente poder rever os amigos. Em teoria, sem abraços. Vamos ver se serei capaz de projetar minha voz de canarinha por cima da emoción e da postura blasé obrigatória" (dia\#70, 22/5).

Em meio a tudo, nossa autora descobriu que estava infectada com a Covid-19, num teste para uma empresa à qual costuma prestar serviços. Foi recomendada imediatamente a contatar sua médica e o serviço de vigilância de saúde, para o rastreamento e comunicação dos contatos havidos nos últimos 15 dias. Dias depois, embora zelosa às regras de isolamento, caminhava na rua, quando recebeu um telefonema, cuja voz feminina perguntava se ela estava em casa. Ao dizer que não, a resposta foi imediata: "Mas como que a senhora não está em casa?! Não viu o resultado de seu teste? A senhora deu positivo para coronavírus e deve se isolar imediatamente" (dia\#84, 5/6).

A descoberta de tal condição, assintomática, levou-a a refletir sobre como poderia ter contraído o vírus: "No meu micromundo, ainda me questiono: onde, de quem e quando cazzus eu peguei coronavírus, se segui a quarentena à risca e mal saí de casa para ir ao mercado, sempre paramentada com máscara, luvas e álcool em gel e buscando manter as distâncias de manual? [...] todo cuidado é pouco - e, inclusive, pode não ser suficiente" (dia\#87, 8/6). Dias antes, em conversa com sua médica, ouviu-a afirmar que “[...] com essa enfermidade, vamos aprendendo a cada dia. A verdade é que é uma incerteza para todos, para vocês e para nós também" (dia\#85, 6/6). Dias depois, ela submeteu-se a um novo teste, temerosa pelas pessoas próximas a si no centro médico - “[...] quantas gotas de saliva expele uma pessoa mascarada ao dizer 'cuidado, tenho coronavírus?"' (dia\#88, 9/6). Sobre o novo resultado, faz uma breve observação aliviada: "Depois de 12 dias de um positivo, sou negativa, livre para comprar meus espinafres na feira again" (dia\#92, 13/6).

34 Durante tais olhares da varanda, ela constata, com autocrítica: “[...] avisto ciclistas passando a toda, superparamentados [...] "Presumo, pela direção que tomam, que sobem rumo a alguma das trilhas nas montanhas que rodeiam a cidade. Não tenho exatamente o perfil de 'policía de balcón', mas bate uma indignação: são três da tarde e essa gente não deveria estar na rua" (dia\#59, 11/5). 
O último dia do diário (\#100, 21/6) coincide com o fim do estado de alarme na Espanha e início oficial do verão no hemisfério norte, ainda que, lembra ela, "o fato de que não houve um boom significativo de novos contágios tem espalhado uma falsa sensação de Superação do Mal"; como afirmam epidemiologistas, "a mensagem é clara, óbvia e cristalina: o vírus segue presente". Além da retomada de temas transversais, como a criação de diversas redes de solidariedade e certa dissolução das mesmas à medida que avançava o desconfinamento, bem como das considerações sobre a solidão e as diversas descobertas, a autora sintetiza aspectos da condição humana: "Eu descobri, talvez como vocês, que o ser humano tem medo, é solidário, egoísta paka, só muda de endereço, é incrível, sempre dá um jeito. Que se reinventa, que ajuda, que é capaz de mudar, que não muda nunca" (dia\#100, 21/6).

\section{Breves ponderações}

Numa rápida retomada dos apontamentos iniciais, é importante situar aspectos que, evidentemente, não esgotam a densidade dos relatos reconstituídos.

Barcelona é conhecida, dentre seus atributos, pelos espaços destinados aos pedestres, como suas ramblas, palavra de origem catalã que remonta, quanto ao sentido de via pública, ao século XIII (Michonneau, 2014, p. 562-563). A própria Susana Bragatto descreve uma rambla específica, o Passeig de Fabra i Puig (relativamente próximo do bairro onde reside):

O amplo calçadão ladeado por duas ruas de uma única faixa e pincelado por filas de árvores é um fenômeno urbano típico de Barcelona, onde os pedestres mandam tanto quanto os carros. Quase todo bairro tem o seu, como uma espinha dorsal ou corazón da vida local, que concentra bares, restaurantes e pequeno comércio. É onde o morador vai tomar um café, fazer o vermute, passear com o cachorro (dia\#73, 25/5). ${ }^{35}$

35 Na época, quase todo o comércio dessa rambla estava fechado, e as regras para a reabertura gradativa despertavam muitas dúvidas (dia\#73, 25/5). 
As vivências dela pelas ruas, narradas até aqui, quase não remetem às ramblas, mas às cercanias de seu apartamento. De toda forma, as ramblas simbolizam certo uso pedestre intensificado que se verifica, sob várias formas e em diferentes horários, por diversos espaços públicos locais, como pude inclusive constatar pessoalmente, nas duas vezes em que visitei Barcelona. ${ }^{36}$ Não é fortuito que nesse contexto tenham surgido obras referenciais de uma antropologia do urbano e das ruas, como a de Manuel Delgado (2007b). ${ }^{37}$ Um de seus enfoques, intitulado "El derecho a la indiferencia" (Delgado, 2007a), interessa mais diretamente: em diálogo com Simmel (1986), ${ }^{38}$ Goffman (1974) e Joseph (1997), o autor refere-se ao anonimato, à reserva, à indiferença mútua e à desatenção cortês como dados constitutivos das interações em espaços urbanos de circulação de transeuntes. Segundo o antropólogo,

[...] la experiencia de la vida pública nunca pierde de vista que quienes la constituyen son personas diferenciadas y diferenciables, pero que esas diferenciaciones son superables a través de un consenso basado en la reserva. Dicho de otro modo, la sociabilidad pública supera la diferencia y la singularidad, sin negarlas. (Delgado, 2007a, p. 191).

Estamos de volta à já citada figura do citadino (Joseph, 2005), imerso nas dinâmicas de copresença nos espaços públicos, cuja atitude blasé constitui, paradoxalmente, a condição da realização seletiva de conversas, encontros ou contatos significativos, cuja sociabilidade decorrente constitui a criação temporária e fugaz de uma igualdade (Joseph, 2005, p. 122-124).

Nos relatos de Susana Bragatto sobre interações nas ruas ou em espaços públicos a partir da pandemia, penso que, sem qualquer pretensão totalizante, as mesmas tornaram-se mais imediatas, distantes ou reservadas (quando não evitadas), dificultadas por temores de contaminação, por desafios de comunicação

36 Em 2000 e 2011. Claro que, em certos casos, a construção mais recente de ramblas pode entrar em conflito com a vida local e pública de um bairro, como no caso dos impactos e rearranjos da Rambla del Raval no bairro de mesmo nome, assinalado por forte diversidade étnica e cultural (Horta, 2010; Pujadas, 2008).

37 À busca de um saber que vai da cidade concebida à cidade praticada (Delgado, 2007b, p. 11-23).

38 Trata-se de tradução para o espanhol de texto já citado anteriormente (em tradução para o português): Simmel (2005). 
sonora ou facial decorrentes de rostos cobertos por máscaras, por eventuais emoções de reencontro afetivo a serem ainda mais controladas, por receio de aproximação ou permanência em espaços com aglomerações. De toda forma, trata-se a meu ver de princípios de sociabilidade presentes há tempo nas dinâmicas de citadinidade, que agora se redefinem a partir de um léxico já existente, mesmo que a pandemia possa levar - não se sabe por quanto tempo - à necessidade da criação de um conjunto de novos códigos básicos de interação cotidiana.

Mas isso leva ao cotejo, mesmo que pontual, de noções de cidadania acionadas durante esse período. Atendo-me novamente apenas ao que já foi enfatizado no diário, percebem-se relações recorrentes, acionadas pelo Estado, entre cidadania e disciplina (para consigo ou com relação a outrem), no sentido de, inicialmente, se respeitar o confinamento, aguardar com paciência pelos testes e denunciar infrações, com adesões ampliadas - malgrado milhares de infrações. A figura da policía de balcón veio a simbolizar a encarnação de tal apelo, assinalada também pela estigmatização de pessoas, como aquelas obrigadas a circular pelas ruas devido a seus ofícios profissionais. O controle da circulação (anterior e presente) daqueles infectados também presentifica uma forma de disciplina, voltada a conter, embora de forma inevitável, a propagação do vírus. Mas a partir da assim chamada desescalada, várias regras estatais se tornam mais complexas e com margem a distintas interpretações, ${ }^{39}$ ao mesmo tempo que se reafirma o apelo à responsabilidade cidadã, por si só insuficientes, como visto, para evitar a formação de aglomerações problemáticas. Nesse caso, pode-se reafirmar que as práticas assumidas pelos citadinos extrapolam um ideário cambiante de cidadania, dadas certas mudanças nas regras básicas a serem seguidas, bem como certa tendência à transgressão das mesmas.

\section{Conclusões: o difícil retorno a São Paulo}

Não escrevi, evidentemente, um diário que pudesse ser contraposto aos preciosos escritos que acabam de ser parcialmente reconstituídos. Mas buscarei

39 O que remete ao tema do cuidado de si como modalidade de assujeitamento (Foucault, 1995), dimensão a ser ainda aprofundada por etnografias ligadas a uma antropologia das subjetividades (Agier, 2015, p. 268-272). 
relatar, em algum diálogo com o diário de Susana Bragatto, e de forma muito enxuta, vivências significativas nesse período, para extrair breves proximidades e distâncias, ainda que não tenha sido possível experienciar e observar cenas de rua como aquelas realizadas e narradas por ela. ${ }^{40}$

A primeira delas concerne ao início do isolamento social, que passei a realizar a partir de $17 / 3 / 2020$, data estipulada pela Reitoria da USP, onde sou docente, para a interrupção parcial de diversas atividades presenciais. A quarentena decretada pelo governo estadual ocorreu somente cinco dias depois, quando muitos já a praticavam. ${ }^{41}$ Se o início do isolamento teve variações quanto à sua demarcação, já que ocorreu sem lockdown, aqueles que conseguiram optar e permaneceram em isolamento (como no meu caso) têm sido obrigados a avaliar se assim permanecem, já que as referências para a tomada de decisão são vagas e incertas. ${ }^{42}$ Ao longo desses meses, tivemos um longo período marcado pelo aumento extremamente preocupante de casos ${ }^{43}$ dada a já citada confluência das crises sanitária, política e econômica no país, todas acirradas continuamente pela condução deliberadamente irresponsável, para dizer o mínimo, por parte do governo federal.

A experiência de Barcelona, próxima a diversas havidas na Europa, apontou um desconfinamento - a partir de diminuição dos índices de casos e óbitos - extremamente desafiante, seguido de certa euforia (um tanto quanto generalizada e ilusória) ligada ao verão, e que deságua agora no drama da assim chamada segunda onda de Covid-19 na Europa, ${ }^{44}$ com contornos nova-

40 Em contraste, acompanhei de perto, em 2014, as aglomerações expressivas de rua havidas na Vila Madalena, onde resido, durante a realização da Copa do Mundo, ocorrida no Brasil (Frúgoli Jr., 2017).

41 Alguns dias antes - quando o Brasil tinha 121 casos de Covid-19, 65\% no estado de São Paulo (o primeiro falecimento ocorreria em $16 / 3 / 2020$, na cidade de São Paulo) - havia consenso entre estudiosos de que era preciso tomar medidas urgentes para conter o crescimento da, então, epidemia (Freire; Alves; Gielow, 2020).

42 Embora, em termos profissionais, as aulas e outras atividades acadêmicas da USP permaneçam remotas.

43 Em meados de junho o Brasil se tornou o segundo país em número de mortes por Covid-19, superando o Reino Unido (Brasil..., 2020). Se tomarmos por exemplo os estágios da pandemia definidos pela Folha de S. Paulo - acelerado, estável, desacelerado e reduzido - e divulgados diariamente para cada estado da federação, ainda nem sequer chegamos, em meados de novembro, ao reduzido.

44 Com novas restrições de circulação na França, Espanha e Portugal (ver detalhes em Balago; Miranda, 2020). 
mente preocupantes. No contexto brasileiro, com flexibilizações prematuras, pressionadas pela dinâmica econômica fragilizada, salvo ações pontuais, pela ausência do Estado, as vivências nos espaços públicos (obrigatória para muitos que sequer puderam se isolar, ou que se expande para aqueles que aos poucos abandonam ou relaxam o isolamento social) revelam-se ainda mais dramáticas. As esperanças projetam-se principalmente nas possíveis vacinas, que embora em andamento em mais de 150 projetos pelo mundo (Pivetta, 2020), indicam até o momento um longo caminho quanto à eficácia, ainda mais se pensadas como solução que exclua o enfrentamento de múltiplos fatores.

Embora o diário analisado faça menções pontuais àqueles mais desamparados - como 600 mil imigrantes ilegais à busca de alguma regularização ou trabalhadores temporários (dia\#31, 13/4) 45 $^{45}$, em nossos contextos urbanos, contingentes mais vulneráveis, como a população de rua, e numa escala muito mais abrangente, habitantes de áreas periféricas mais precárias, passaram a constituir agentes e espaços crescentemente atingidos pela Covid-19 - sobretudo pessoas negras e pardas, com possibilidades reduzidas ou inexistentes de praticar isolamento, ou mais expostas aos riscos dos transporte públicos lotados (mesmo sob os novos protocolos, que facilmente se tornam palavras vazias e sem qualquer eficácia).

Manifestações políticas mais explícitas tiveram início, em São Paulo e outras metrópoles, quando dos panelaços, nas janelas ou sacadas, em geral no início da noite, contra o presidente, sobretudo quando negou, em cadeia nacional, a dimensão letal do coronavírus e atacou a quarentena (24/3/2020). Semanas depois, contudo, houve carreatas pelo final do isolamento, ${ }^{46}$ seguidas de manifestações na Av. Paulista, envolvendo grupos pró e contra ${ }^{47}$ as posições do presidente, com certa retomada da polarização já em curso há alguns anos, seguida de protestos ligados ao movimento Black Lives Matter (com maior visibilidade das múltiplas manifestações havidas nos Estados Unidos).

45 "Eles costumam chegar em bandos de até 150 mil entre abril e junho para a colheita de cereja, pêssego e nectarina, vindos de países tão díspares como Romênia, Marrocos e Senegal" (dia\#31, 13/4).

46 As ocorridas em São Paulo em 19/4/2020 também pediam intervenção militar, com a promoção de buzinaços "em frente ou nas imediações dos hospitais Moriah, Ruben Berta, Edmundo Vasconcelos, HCor, Santa Catarina e Pro Matre" (Carreatas..., 2020).

47 Dentre esses, integrantes de torcidas organizadas. 
Como milhões de outras pessoas, passei a trabalhar em casa, cumprindo sistematicamente, com minha esposa, o isolamento, ${ }^{48}$ fazendo contatos virtuais regulares com familiares e também amigos, mais atento às possibilidades de uso dos espaços domésticos e às paisagens da sacada do meu apartamento. Um problema de saúde obrigou-me (tenho mais de 60 anos e integro os grupos de risco ${ }^{49}$ ) a interromper o trabalho, ir a consultas médicas, fazer exames de laboratório e me submeter a uma pequena cirurgia, que correu bem e não deixou infecções, em boa parte porque meu plano de saúde propiciou-me o uso de um ótimo hospital privado.

Durante tais saídas, foi possível ver de relance, pela janela do carro, a forte presença de entregadores pelas ruas (de moto ou de bicicleta), cujo papel se intensificou a partir da pandemia,;0 avistei várias cenas de interação nas calçadas, sobretudo entre os mais jovens, sem quaisquer cuidados necessários (como uso de máscara ou distâncias devidas), além de um gradativo aumento, ao longo do tempo, de pessoas e de veículos pelas ruas. A partir de então, voltei a recriar uma rotina de trabalho - aulas, reuniões, seminários, orientações, bancas, participação em congressos, entrevistas, etc. - dentro de casa, com diminuição de atividades corporais, ${ }^{51}$ e sob a ausência, como se sabe, de um horizonte claro de mudança a curto ou médio prazo.

48 Segundo o Datafolha, em 17/4/2020, dia em que foram confirmadas 210 mortes no país, $21 \%$ de brasileiros declaravam-se em isolamento completo, e $50 \%$ saíam de casa apenas quando inevitável; em 11/8/2020 (quando houve 1274 óbitos), tais taxas tinham caído, respectivamente, para 8\% e 43\% (Amâncio, 2020).

49 Recentemente, a Faculdade de Saúde Pública da USP propôs substituir termo "grupo de risco" pelo conceito de fatores de risco, já que o primeiro, durante a pandemia de HIV, levou à circunscrição dos 4 Hs (homossexuais, hemofílicos, dependentes de heroína e imigrantes haitianos) e deixou $20 \%$ dos casos iniciais sem classificação (mulheres, crianças e homens heterossexuais). A proposta estabelece fatores de risco para eventos desfavoráveis - infecção, doença severa e morte por SARS-CoV-2 - com base em evidências como obesidade, tabagismo, cânceres, doença neurológica, imunodeficiências e hipertensão arterial sistêmica, com atenção especial a pessoas com mais de 60 anos, não brancas e com privações socioeconômicas (Faculdade de Saúde Pública da USP, 2020).

50 Diversas reportagens e documentários passaram a ressaltar o crescente papel desses profissionais, submetidos em geral a plataformas digitais que os obrigam a longas e malremuneradas jornadas de trabalho (ver, a respeito, a fala de Eduardo Rumenig, pesquisador do tema em São Paulo, em Grupo de Estudos de Antropologia da Cidade, 2020).

51 Parei de nadar, hábito regular por anos, e diminuí a prática de caminhadas. Sobre riscos e consequências de mudanças na rotina devido à Covid-19, ver Zorzetto (2020). 
Em recentes saídas à rua, ainda definidas pela necessidade, é fácil perceber, com apreensão - e em certa sintonia com os escritos de Susana Bragatto -, que o isolamento social se torna algo cada vez mais residual, pela forma como certos espaços públicos voltam a ser crescentemente ocupados. Paradoxalmente, sinais básicos de vida urbana suscitam inquietações. Entendo que, para um significativo contingente de pessoas, o trabalho em casa nem tenha sido uma opção, e que isso passa por clivagens de classe, gênero, raça, geração e território. De toda forma, a disseminação oscilatória da Covid-19 prossegue e demanda enfrentamentos crescentes.

Nessa constelação de incertezas, é fundamental prosseguir com pesquisas e reflexões sobre os significados da vida urbana a partir de agora, ${ }^{52}$ seja com relação às cidades próximas à realidade europeia - cujas imagens de esvaziamento radical e reocupações significativas proliferam -, seja quanto a cidades que transcendem esse modelo, com o caso das metrópoles brasileiras, mais fragmentadas internamente, cujo esvaziamento oscilante e reativação dos seus espaços obedecem a ritmos e determinações de outras ordens.

Numa época tão distópica, agudizada por isolamentos necessários, mas difíceis, quando uma simples saída à rua envolve tantas precauções, ganha um novo sentido a ideia de que "a cidade esconde esses tesouros triviais, mas incomensuráveis, verdadeiros multiplicadores de sonhos" (Paquot, 2010, p. 40, tradução minha). ${ }^{53}$ Como argumentei neste artigo, entendo que é fundamental olhar, numa perspectiva renovada, a contrapontos clássicos - como casa e rua, ou cidadania e citadinidade - à busca da compreensão de como as diversas interações face a face da vida urbana cotidiana, uma prática constitutiva de nossas relações, podem vir a ser refeitas, com atenção àquelas de domínio mais popular, em meio a esse turbilhão que nos acomete.

52 Ver a respeito, no campo da antropologia urbana paulista, Toledo e Souza Jr. (2020).

53 No original: "La ville recèle de ces trésors anodins mais incommensurables, de véritables démultiplicateurs de songes." 


\section{Referências}

AGIER, M. O sexo da pobreza. Homens, mulheres e famílias numa 'avenida' em Salvador da Bahia. Tempo Social, São Paulo, n. 2, p. 35-60, 1990.

AGIER, M. Situações elementares da vida urbana. In: AGIER, M. Antropologia da cidade: lugares, situações, movimentos. São Paulo: Terceiro Nome, 2011. p. 89-100.

AGIER, M. Migrações, descentramento e cosmopolitismo: uma antropologia das fronteiras. Maceió: Edufal; São Paulo: Edunesp, 2015.

AMÂNCIO, T. Isolamento despenca, enquanto sobe o otimismo com a pandemia, mostra Datafolha. Folha de S. Paulo, São Paulo, 18 ago. 2020. Disponível em: https://www1. folha.uol.com.br/equilibrioesaude/2020/08/isolamento-despenca-enquanto-sobe-otimismo-com-a-pandemia-mostra-datafolha.shtml. Acesso em: 12 nov. 2020.

BALAGO, R.; MIRANDA, G. Europa reage a nova alta de casos de Covid com medidas duras. Folha de S. Paulo, São Paulo, p. A15, 15 out. 2020.

BRAGATTO, S. Diário de confinamento. Folha de S. Paulo, São Paulo, 14 mar./21 jun. 2020.

BRASIL passa o Reino Unido e se torna o segundo país com mais mortes por Covid19. Folha de S. Paulo, São Paulo, 12 jun. 2020. Disponível em: https://wwwl.folha.uol. com.br/equilibrioesaude/2020/06/brasil-passa-reino-unido-e-se-torna-o-2o-pais-com-mais-mortes-por-covid-19.shtml. Acesso em: 12 nov. 2020.

CARREATAS pelo país têm Bolsonaro, pedidos de reabertura do comércio e avenida Paulista fechada. Folha de S. Paulo, São Paulo, 19 abr. 2020. Disponível em: https:// www1.folha.uol.com.br/poder/2020/04/carreatas-pelo-pais-pedem-fim-do-isolamento-apos-206-novas-mortes-por-coronavirus.shtml. Acesso em: 15 nov. 2020.

CHARBEL, F. Dia após dia após dia após dia. Serrote, São Paulo, edição especial, p. 113131, jul. 2020. Disponível em: https://www.revistaserrote.com.br/wp-content/uploads/2020/07/serrote-especial-em-quarentena.pdf. Acesso em: 1 ago. 2020.

CUÉ, C. E.; PÉREZ, C.; BLAS, E. G. Espanha decreta "estado de alarme" por 15 dias por coronavírus. El País (Brasil), São Paulo, 13 mar. 2020. Disponível em: https://brasil. elpais.com/internacional/2020-03-13/espanha-decreta-estado-de-alarme-por-15-dias.html. Acesso em: 30 jul. 2020.

DAMATTA, R. Carnavais, malandros e heróis: para uma sociologia do dilema brasileiro. 2. ed. Rio de Janeiro: Zahar, 1980. 
DAMATTA, R. A casa e a rua: espaço, cidadania, mulher e morte no Brasil. São Paulo: Brasiliense, 1985.

DELGADO, M. El derecho a la indiferencia. In: DELGADO, M. Sociedades movedizas: pasos hacia uma antropología de las calles. Barcelona: Anagrama, 2007a. p. 182-201.

DELGADO, M. Sociedades movedizas: pasos hacia uma antropología de las calles. Barcelona: Anagrama, 2007b.

FACULDADE DE SAÚDE PÚBLICA DA USP. Carta aberta da Congregação da Faculdade de Saúde Pública da Universidade de São Paulo. São Paulo: FSP, 22 out. 2020.

FOUCAULT, M. O sujeito e o poder. In: DREYFUS, H.; RABINOW, P. Michel Foucault, uma trajetória filosófica: para além do estruturalismo e da hermenêutica. Rio de Janeiro: Forense Universitária, 1995. p. 231-249.

FREEMAN, J. Outono em Nova York. Folha de S. Paulo, São Paulo, p. C8, 11 out. 2020.

FREIRE, V. T.; ALVES, G.; GIELOW, I. Contra epidemia de coronavírus, Brasil precisa parar, afirmam especialistas. Folha de S. Paulo, São Paulo, 14 mar. 2020. Disponível em: https://www1.folha.uol.com.br/equilibrioesaude/2020/03/contra-epidemia-brasil-precisa-parar-afirmam-especialistas.shtml. Acesso em: 31 jul. 2020.

FRÚGOLI Jr., H. O legado de 'Carnavais' de Roberto DaMatta. Jornal da Tarde, São Paulo, 16 dez. 2000. Caderno de Sábado, p. 5.

FRÚGOLI Jr., H. Sociabilidade urbana. Rio de Janeiro: Zahar, 2007.

FRÚGOLI Jr., H. The 2014 World Cup on the streets of Vila Madalena (São Paulo). In: FERRO, L. et al. (ed.). Moving cities: contested views on urban life. Wiesbaden: Springer, 2017. p. 77-95.

GEERTZ, C. Obras e vidas: o antropólogo como autor. Rio de Janeiro: Ed. UFRJ, 2002.

GEERTZ, C. "Do ponto de vista dos nativos": a natureza do entendimento antropológico. In: GEERTZ, C. O saber local: novos ensaios em antropologia interpretativa. 6. ed. Petrópolis: Vozes, 2003. p. 85-107.

GOFFMAN, E. Relaciones en público: microestudios de orden público. Madrid: Alianza, 1974.

GOFFMAN, E. Ritual de interação: ensaios sobre o comportamento face a face. Petrópolis: Vozes, 2011. 
GRUPO DE ESTUDOS DE ANTROPOLOGIA DA CIDADE. Ciclo de Seminários do GEAC: impactos e desafios de pesquisa durante a pandemia de Covid-19. Sessão 1: Ciclistas entregadores de plataformas digitais. São Paulo: GEAC, 26 ago. 2020. 1 vídeo (55 min). Disponível em: https://www.facebook.com/grupoestudosdeantropologiadacidade/ videos/699448560638178. Acesso em: 14 nov. 2020.

HORTA, G. Rambla del Raval de Barcelona: de apropriaciones viandantes y procesos sociales. Barcelona: El Viejo Topo, 2010.

JOSEPH, I. Le migrant comme tout venant. In: DELGADO, M. (ed.). Ciutat i immigració. Barcelona: Centre de Cultura Contemporània de Barcelona, 1997. p. 177-188.

JOSEPH, I. Erving Goffman e a microssociologia. Rio de Janeiro: Ed. FGV, 2000.

JOSEPH, I. A respeito do bom uso da Escola de Chicago. In: VALLADARES, L. P. (org.). A Escola de Chicago: impactos de uma tradição no Brasil e na França. Belo Horizonte: Ed. UFMG; Rio de Janeiro: Iuperj, 2005. p. 91-128.

LATOUR, B. Se o Brasil achar solução para si, vai salvar o resto do mundo (entrevista de Ana Carolina Amaral). Folha de S. Paulo, São Paulo, p. B6, 12 set. 2020.

MALINOWSKI, B. Um diário no sentido estrito do termo. Rio de Janeiro: Record, 1997.

McCALLUM, C.; BUSTAMANTE, V. Parentesco, gênero e individuação no cotidiano da casa em um bairro popular de Salvador da Bahia. Etnográfica, Lisboa, v. 16, n. 2, p. 221-246, 2012.

MICHONNEAU, S. Rambla. In: TOPALOV, C. et al. (org.). A aventura das palavras da cidade, através dos tempos, das línguas e das sociedades. São Paulo: Romano Guerra, 2014. p. 561-569.

MILLER, D. Como conduzir uma etnografia durante o isolamento. Tradução de Lucca Palmieri e legendagem em português de Joaquim Antônio Silva. São Paulo: Laboratório de Imagem e Som em Antropologia, 20 maio 2020. 1 vídeo (20 min). Disponível em: https://www.youtube.com/watch?v=WC24b3nzp98. Acesso em: 29 jul. 2020.

PAQUOT, T. L’espace public. Paris: La Découverte, 2009.

PAQUOT, T. Petits riens urbains. Revue Urbanisme, Paris, n. 370, p. 39-40, 2010.

PARK, R. E. A cidade: sugestões para a investigação do comportamento humano no meio urbano. In: VELHO, O. G. (org.). O fenômeno urbano. 4. ed. Rio de Janeiro: Guanabara, 1987. p. 26-67.

PEIXOTO, F. A. Antropólogos procuram ‘lógica brasileira' nas teias do jogo do bicho. Jornal da Tarde, São Paulo, 17 jul. 2000. Caderno de Sábado, p. 3. 
PIGLIA, R. Anos de formação: os diários de Emilio Renzi. São Paulo: Todavia, 2017.

PIGLIA, R. Os anos felizes: os diários de Emilio Renzi. São Paulo: Todavia, 2019.

PINA-CABRAL, J.; GODOI, E. P. Apresentação: Dossiê Vicinalidades e Casas Partíveis. Revista de Antropologia, São Paulo, v. 57, n. 2, p. 11-21, 2014.

PIVETTA, M. A procura de atalhos: equipes internacionais recorrem a oito técnicas e criam 150 candidatas a vacina contra a Covid-19 em seis meses. Pesquisa Fapesp, São Paulo, ano 21, n. 293, p. 18-23, jul. 2020.

PUJADAS, J. J. A rua como espaço público de sociabilidade: um olhar comparativo. In: CORDEIRO, G. Í.; VIDAL, F. (org.). A rua: espaço, tempo, sociabilidade. Lisboa: Livros Horizonte, 2008. p. 143-154.

SIMMEL, G. Las grandes urbes y la vida del spíritu. In: SIMMEL, G. El individuo y la libertad. Barcelona: Península, 1986. p. 29-34.

SIMMEL, G. As grandes cidades e a vida do espírito. Mana, Rio de Janeiro, v. 11, n. 2, p. 577-591, 2005.

SIMMEL, G. A sociabilidade (exemplo de sociologia pura ou formal). In: SIMMEL, G. Questões fundamentais da sociologia. Rio de Janeiro: Zahar, 2006. p. 59-82.

TOLEDO, L. H.; SOUZA Jr., R. A. P. Sociabilidade pandêmica? O que uma antropologia urbana pode dizer a respeito da crise deflagrada pela Covid-19. Cadernos de Campo, São Paulo, v. 29, n. supl., p. 53-64, 2020.

UNITED NATIONS HUMAN SETTLEMENTS PROGRAMME. UN-Habitat key message on COVID-19 and public space. Nairobi, May 2020. Disponível em: https://unhabitat.org/sites/default/files/2020/05/unh_covid-19_ps_key_message.pdf. Acesso em: 5 out. 2020 .

VOGEL, A.; MELLO, M. A. S. Quando a rua vira casa: a apropriação de espaços de uso coletivo em um centro de bairro. 4. ed. Niterói: Eduff, 2016.

ZORZETTO, R. Tempos de incerteza: mudanças na rotina ocasionadas pela Covid-19 podem aumentar casos de sofrimento emocional e transtornos mentais. Pesquisa Fapesp, São Paulo, ano 21, n. 294, p. 18-23, ago. 2020.

Recebido: 04/08/2020 Aceito: 27/10/2020 | Received: 8/4/2020 Accepted: 10/27/2020 